\title{
Recyclable Magnetite Nanoparticle Catalyst for One-Pot Conversion of Cellobiose to 5-Hydroxymethylfurfural in Water
}

\author{
Anuja Bhalkikar, Zane C. Gernhart, and Chin Li Cheung \\ Department of Chemistry, University of Nebraska-Lincoln, Lincoln, NE 68588, USA \\ Correspondence should be addressed to Chin Li Cheung; ccheung2@unl.edu
}

Received 20 August 2015; Accepted 29 September 2015

Academic Editor: Hassan Karimi-Maleh

Copyright (C) 2015 Anuja Bhalkikar et al. This is an open access article distributed under the Creative Commons Attribution License, which permits unrestricted use, distribution, and reproduction in any medium, provided the original work is properly cited.

\begin{abstract}
Environmentally benign and easily recoverable magnetite nanoparticles $\left(\mathrm{Fe}_{3} \mathrm{O}_{4} \mathrm{NPs}\right)$ were demonstrated to catalyze the one-pot conversion of cellobiose, a glucose disaccharide, to 5-hydroxymethylfurfural (5-HMF). The conversion was achieved in water under hydrothermal conditions. The catalytic activity of $\mathrm{Fe}_{3} \mathrm{O}_{4}$ NPs surpassed those of iron (II) and iron (III) chlorides in this reaction. Optimized cellobiose conversion reactions catalyzed with $\mathrm{Fe}_{3} \mathrm{O}_{4} \mathrm{NPs}$ gave the highest 5-HMF yields of $23.4 \pm 0.6 \%$ at $160^{\circ} \mathrm{C}$ for 24 hours. After three reuses, the $\mathrm{Fe}_{3} \mathrm{O}_{4} \mathrm{NP}$ catalyst retained its catalytic activity with similar 5-HMF yields, demonstrating the recyclability of this eco-friendly catalyst in water.
\end{abstract}

\section{Introduction}

Magnetite nanoparticles $\left(\mathrm{Fe}_{3} \mathrm{O}_{4} \mathrm{NPs}\right)$ have been extensively applied in various technological areas such as bioseparation, target drug delivery, immunoassays, and magnetic resonance imaging because of their magnetic properties, nanosize, and high surface-area-to-volume ratio [1-3]. In the past couple of years, $\mathrm{Fe}_{3} \mathrm{O}_{4}$ NPs have been widely studied as catalysts [4] and catalyst supports $[5,6]$ for heterogeneous catalysis. For example, $\mathrm{Fe}_{3} \mathrm{O}_{4} \mathrm{NPs}$ were demonstrated to independently catalyze Fenton's reaction [7]. Owing to their nanosize, large surface area, and basic sites on their surfaces, $\mathrm{Fe}_{3} \mathrm{O}_{4}$ NPs were also demonstrated to catalyze ozonation of parachlorobenzoic acid [8].

Recently, catalysts composed of active functional groups immobilized on $\mathrm{Fe}_{3} \mathrm{O}_{4}$ NPs have been widely studied for the catalytic production of industrial chemical precursors from renewable resources because of the ease of retrieving $\mathrm{Fe}_{3} \mathrm{O}_{4}$ NPs using magnetic methods $[9,10]$. Particularly, these catalysts composed of magnetic cores are fast emerging as viable alternatives to homogeneous catalysts in biomass processing $[11,12]$ as well as for the synthesis of platform chemicals such as 5-ethoxymethylfurfural [13], 2,5-furandicarboxylic acid [14], and 5-hydroxymethylfurfural (5-HMF) [15] in the presence of organic solvents from sustainable biomass.
With an estimated current global market of about 100 tonnes per year [16], 5-HMF has been recognized as one promising renewable platform chemical because it can serve as a carbon neutral feedstock for over a dozen important industrial biopolymer and biofuel precursors $[17,18]$. Most early bench scale efforts to produce 5-HMF focused on using fructose as a starting material due to its ease of dehydration to 5-HMF with Brønsted acid catalysts or metal salts in the presence of biphasic systems of organic solvents and ionic liquids [19-25]. Recently, there have also been intense research efforts to directly produce 5-HMF from cellulose, the most abundant plant-based polymer of glucose on Earth $[26,27]$. The use of cellulose as a starting material is attractive because of its comparatively low cost and large natural abundance [28]. In this case, the formation of 5-HMF typically involves the breaking of the $\beta$-(1,4)-glycosidic bonds linking the glucose monomers in cellulose, followed by isomerization of glucose to fructose and then dehydration of fructose to 5-HMF [29, 30]. Though acids and metal salts have been successfully shown to catalyze the conversions of fructose and cellulose into 5-HMF in biphasic media, the application of voluminous amounts of homogeneous acids is not industrially viable because these acids can corrode reactors [23, 31]. Also, the recovery of the homogeneous metal salt catalysts is difficult. Diverse heterogeneous materials ranging from 
acidic polymers and traditional metal oxides to phosphate catalysts applied with organic solvents have also been demonstrated for 5-HMF synthesis [23]. Nevertheless, organic solvents are environmentally toxic. Hence, designing cost effective heterogeneous catalysts for use in reactions where water is the sole solvent is a significant next step for sustainable production of 5-HMF [32].

Herein, we report our study of $\mathrm{Fe}_{3} \mathrm{O}_{4} \mathrm{NP}$ catalyst for the one-pot conversion of cellobiose to 5-HMF in aqueous media under hydrothermal conditions. To the best of our knowledge, the application of environmentally safe, easily recoverable $\mathrm{Fe}_{3} \mathrm{O}_{4}$ NPs as catalysts for the production of 5-HMF in aqueous media has not yet been reported. Cellobiose, the smallest repeating disaccharide unit of cellulose, was used as a model feedstock to investigate the effectiveness of $\mathrm{Fe}_{3} \mathrm{O}_{4} \mathrm{NPs}$ at breaking the $\beta$ - $(1,4)$-glycosidic bond between the glucose units and the formation of 5-HMF from it. Cellulose was not investigated in our current study since its breakdown in an aqueous medium is known to be difficult due to its hydrogen bonding network. The catalytic activity of $\mathrm{Fe}_{3} \mathrm{O}_{4} \mathrm{NP}$ catalyst on 5-HMF production was evaluated and compared with those of common iron chloride salts. The reusability of these $\mathrm{Fe}_{3} \mathrm{O}_{4} \mathrm{NPs}$ was examined by multiple recycling experiments. The effect of $\mathrm{Fe}_{3} \mathrm{O}_{4}$ NPs on the dehydration of glucose and fructose was investigated to elucidate the potential mechanism for the conversion of cellobiose to 5-HMF.

\section{Materials and Methods}

2.1. Materials. D-Fructose (99\%), D-glucose, 5-hydroxymethylfurfural (5-HMF) (99\%), iron (II) chloride tetrahydrate $\left(\mathrm{FeCl}_{2} \cdot 4 \mathrm{H}_{2} \mathrm{O}, 98 \%\right)$, iron (III) chloride hexahydrate $\left(\mathrm{FeCl}_{3} \cdot 6 \mathrm{H}_{2} \mathrm{O}\right.$, ACS reagent grade), and sulfuric acid $\left(\mathrm{H}_{2} \mathrm{SO}_{4}\right.$, 99.999\%, HPLC grade) were purchased from Sigma-Aldrich (St. Louis, MO). D-Cellobiose $(98+\%)$ was obtained from Alfa Aesar (Ward Hill, MA). Ammonium hydroxide $\left(\mathrm{NH}_{3} \cdot \mathrm{H}_{2} \mathrm{O}\right.$, Certified ACS Plus) was purchased from Fischer Scientific (Waltham, MA). All purchased chemicals were used as received. $18 \mathrm{M} \Omega \cdot \mathrm{cm}$ deionized water was generated using a Synergy filtration system (VWR, Radnor, PA).

2.2. Synthesis and Characterization of $\mathrm{Fe}_{3} \mathrm{O}_{4} N P s$. $\mathrm{Fe}_{3} \mathrm{O}_{4} \mathrm{NPs}$ were synthesized using a reported coprecipitation technique in an alkaline solution [33]. Briefly, $11.7 \mathrm{~g}$ of $\mathrm{FeCl}_{3} \cdot 6 \mathrm{H}_{2} \mathrm{O}$ and $4.3 \mathrm{~g}$ of $\mathrm{FeCl}_{2} \cdot 4 \mathrm{H}_{2} \mathrm{O}$ were slowly dissolved in $250 \mathrm{~mL}$ of deionized water under nitrogen atmosphere while being vigorously stirred at room temperature. $50 \mathrm{~mL}$ of $28 \% \mathrm{NH}_{3} \cdot \mathrm{H}_{2} \mathrm{O}$ was added dropwise to the reaction mixture which was then stirred for 2 hours. Black particles formed in the reaction were separated using a magnet and thoroughly washed with deionized water three times. The products were left to dry under ambient conditions overnight before use.

The morphology of the as-prepared $\mathrm{Fe}_{3} \mathrm{O}_{4}$ NPs was examined by transmission electron microscopy (TEM) using a Hitachi H7500 TEM operated at $80 \mathrm{kV}$. The crystal structure of as-synthesized $\mathrm{Fe}_{3} \mathrm{O}_{4}$ NPs and recycled $\mathrm{Fe}_{3} \mathrm{O}_{4}$ NPs was examined using a PANalytical Empyrean diffractometer (PANalytical, Westborough, MA). The X-ray source was operated at $45 \mathrm{kV}$ and $40 \mathrm{~mA}$ current to generate $\mathrm{Cu} \mathrm{K} \alpha$ X-ray with an average wavelength of $1.544 \AA$. The surface area of $\mathrm{Fe}_{3} \mathrm{O}_{4}$ NPs was determined by the Brunauer-Emmett-Teller (BET) method using an ASAP 2020 Analyzer (Micromeritics Instrument Corporation, Norcross, GA) and nitrogen.

2.3. Catalytic Reactions with $\mathrm{Fe}_{3} \mathrm{O}_{4} \mathrm{NPs}$ and Iron-Based Salts. Experiments for the conversion reactions were carried out in Teflon-lined stainless steel autoclave Parr vessels (Vessel number 4744, Parr Instrument, Moline, IL). In a typical experiment, $0.02 \mathrm{~g}$ of the iron-based catalyst was added to $10 \mathrm{~mL}$ of a $50 \mathrm{mM}$ cellobiose aqueous solution in a Teflon liner. The assembled stainless steel autoclave was heated at $160^{\circ} \mathrm{C}$ and maintained at this temperature for 24 hours. After the autoclave was cooled to room temperature, the identities and concentrations of products were analyzed by high pressure liquid chromatography (HPLC). Control experiments were conducted without the catalysts. The experiments were performed in triplicate. Experiments were repeated with glucose and fructose as the carbon source reactants under the same reaction conditions. The product yields were reported as average values from the triplicates and the uncertainty of these values was estimated as the standard deviation of the mean. Note that we had also studied the cellobiose conversion reactions at various reaction temperatures ranging from $140^{\circ} \mathrm{C}$ to $180^{\circ} \mathrm{C}$ and with various reaction times from 12 hours to 72 hours. Only yield data of reactions at $160^{\circ} \mathrm{C}$ and with reaction time of 24 hours were reported because this condition gave the best product yields for the cellobiose conversion to 5 -HMF.

2.4. HPLC Analysis. The products from the cellobiose conversion experiments were analyzed by HPLC using a method developed at the National Renewable Energy Laboratory [34]. Before each HPLC analysis, the product mixtures from the experiments were first centrifuged and then filtered through a $0.2 \mu \mathrm{m}$ polytetrafluoroethylene syringe filter (VWR, Radnor, PA) to remove any solid catalysts. The identification and quantification of products in the filtrates were performed on an Aminex HPX-87H column (Bio-Rad Laboratories, Inc., Hercules, CA) equipped with a Waters 410 Differential Refractometer (Waters, Milford, MA). $5 \mathrm{mM}$ sulfuric acid was used as the mobile phase at a flow rate of $0.6 \mathrm{~mL} / \mathrm{min}$. The column and the detector were maintained at $55^{\circ} \mathrm{C}$ and $35^{\circ} \mathrm{C}$, respectively. Samples of cellobiose, glucose, fructose, and 5$\mathrm{HMF}$ in water were prepared and used as standards to obtain the calibration curves for the quantification of these chemicals in the reaction products. The identifications of acetic acid, formic acid, levulinic acid, lactic acid, hydroxyacetone, and 1,6-anhydroglucose were also determined by HPLC. The formation of fructose was confirmed by HPLC analysis using an Alltech Alltima amino 100A column (Grace, Columbia, $\mathrm{MD})$ at Microbac Laboratories, Inc. (Boulder, CO).

The calculations for conversion of cellobiose to $5-\mathrm{HMF}$ and conversion of glucose to 5-HMF were performed using the following formulae:

Cellobiose conversion (\%)

$$
=\frac{[\text { Cellobiose }]_{\mathrm{I}}-[\text { Cellobiose }]_{\mathrm{F}}}{[\text { Cellobiose }]_{\mathrm{I}}} \times 100 \%,
$$


Glucose yield from cellobiose (\%)

$$
=\frac{[\text { Glucose }]_{\mathrm{F}}}{[\text { Cellobiose }]_{\mathrm{I}} \times 2} \times 100 \%,
$$

Fructose yield from cellobiose (\%)

$$
=\frac{[\text { Fructose }]_{\mathrm{F}}}{[\text { Cellobiose }]_{\mathrm{I}} \times 2} \times 100 \%,
$$

5-HMF yield from cellobiose (\%)

$$
=\frac{[5-\mathrm{HMF}]_{\mathrm{F}}}{[\text { Cellobiose }]_{\mathrm{I}} \times 2} \times 100 \%,
$$

Glucose conversion (\%)

$$
=\frac{[\text { Glucose }]_{\mathrm{I}}-[\text { Glucose }]_{\mathrm{F}}}{[\text { Glucose }]_{\mathrm{I}}} \times 100 \%,
$$

$5-\mathrm{HMF}$ yield from glucose $(\%)=\frac{[5-\mathrm{HMF}]_{\mathrm{F}}}{[\text { Glucose }]_{\mathrm{I}}} \times 100 \%$,

where subscripts I and F represent the initial and final concentrations of cellobiose (glucose, fructose, or 5-HMF). The calculations and formulae for fructose conversion and corresponding 5-HMF yield were similar to those for the reactions with glucose as the precursor.

\section{Results and Discussion}

3.1. Physical and Structural Characterization of $\mathrm{Fe}_{3} \mathrm{O}_{4} \mathrm{NPs}$. $\mathrm{Fe}_{3} \mathrm{O}_{4}$ NPs were synthesized using a coprecipitation method to yield a black product. TEM images of the as-synthesized $\mathrm{Fe}_{3} \mathrm{O}_{4}$ NPs showed that their sizes ranged from $10 \mathrm{~nm}$ to $30 \mathrm{~nm}$ (Figure 1). The XRD pattern of these $\mathrm{Fe}_{3} \mathrm{O}_{4} \mathrm{NPs}$ matched that of $\mathrm{Fe}_{3} \mathrm{O}_{4}$ when indexed according to the ICDD data card \# 01-089-4319, confirming the identity of the NPs (Figure 2). From BET measurements, the surface area of the $\mathrm{Fe}_{3} \mathrm{O}_{4} \mathrm{NPs}$ was found to be $72.4 \mathrm{~m}^{2} / \mathrm{g}$.

3.2. Catalytic Activities of Iron-Based Catalysts on the Conversion of Cellobiose to 5-HMF. Common divalent and trivalent iron salts $\left(\mathrm{FeCl}_{2}, \mathrm{FeCl}_{3}\right)$ have been utilized for the breakdown of hemicellulose and cellulose as well as for 5-HMF synthesis because of their strong Lewis acidity and basicity [35-37]. In order to compare the catalytic performance of the heterogeneous and homogeneous iron-based systems, the conversion of cellobiose to 5-HMF was evaluated in the presence of $\mathrm{Fe}_{3} \mathrm{O}_{4} \mathrm{NPs}, \mathrm{FeCl}_{2}$, and $\mathrm{FeCl}_{3}$ (Figure 3(a)). The conversion reaction was performed using the optimized reaction parameters of $160^{\circ} \mathrm{C}$ for 24 hours under hydrothermal conditions. Cellulose is known to undergo near complete conversion under hydrothermal conditions to form numerous degradation products $[38,39]$. For our experiments under hydrothermal conditions, cellobiose conversion of $\sim 99 \%$ was obtained irrespective of the presence or the absence of the catalyst. Cellobiose was postulated to undergo hydrolysis to form glucose which further reversibly isomerized to fructose and some

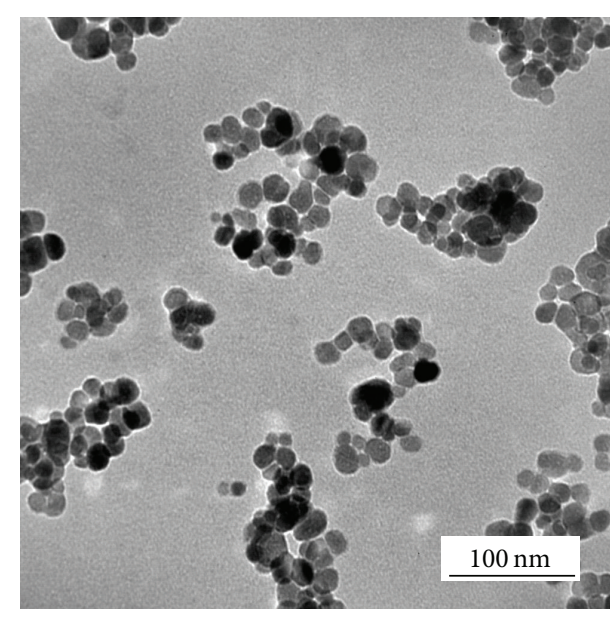

FIgURE 1: TEM image of $\mathrm{Fe}_{3} \mathrm{O}_{4}$ NPs.

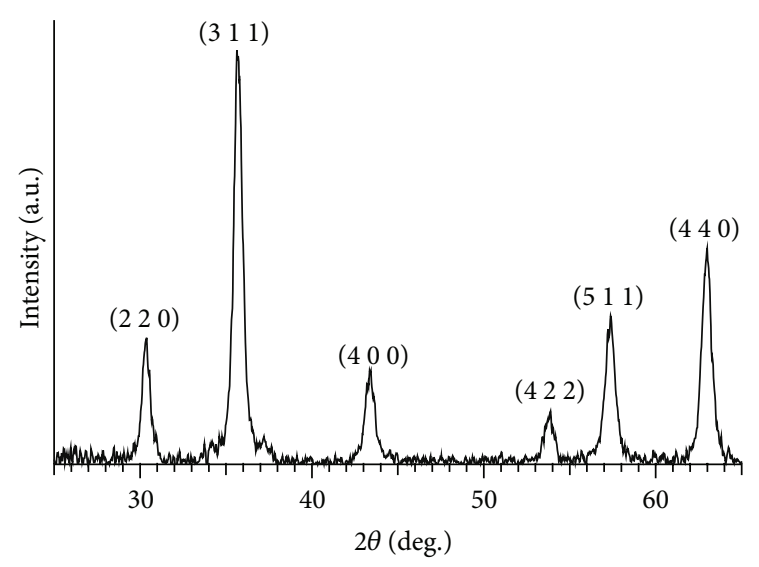

Figure 2: XRD pattern of $\mathrm{Fe}_{3} \mathrm{O}_{4}$ NPs.

unstable reaction intermediates. 5-HMF was finally formed as a consequence of the dehydration of fructose [30, 31, 40, 41].

Reactions with $\mathrm{Fe}_{3} \mathrm{O}_{4}$ NPs produced the highest 5-HMF yield of $23.4 \pm 0.6 \%$ while that with control experiment with no catalysts gave merely $10.8 \pm 0.6 \%$, suggesting unquestionable influence of the NPs in these reactions. Additionally, the iron salts underperformed in the 5-HMF yields as compared to $\mathrm{Fe}_{3} \mathrm{O}_{4}$ NPs. This indicates that both iron (II) and iron (III) ions are not effective in predominantly converting cellobiose to 5-HMF. Using these results, we conclude that any potentially leached iron ions from $\mathrm{Fe}_{3} \mathrm{O}_{4}$ NPs are not expected to have significant effect on the product yields. Also, hydrolysis of iron salts in an aqueous medium can lead to the formation of iron complexes and acids which are known to increase side products formation, leading to a decline in the 5-HMF yields [42]. Hence, the high 5-HMF yields obtained with the $\mathrm{Fe}_{3} \mathrm{O}_{4}$ NPs are mainly resulting from magnetite as the catalyst. Glucose and fructose were identified as the major by-products of this reaction (Figure 3(b)). We note that the reversible glucose to fructose isomerization was also improved wherein higher fructose yields were obtained with $\mathrm{Fe}_{3} \mathrm{O}_{4}$ NPs $(3.1 \pm 0.3 \%)$ as opposed to when $\mathrm{FeCl}_{2}(0.9 \pm 0.1 \%)$ or $\mathrm{FeCl}_{3}(0.3 \pm 0.1 \%)$ 


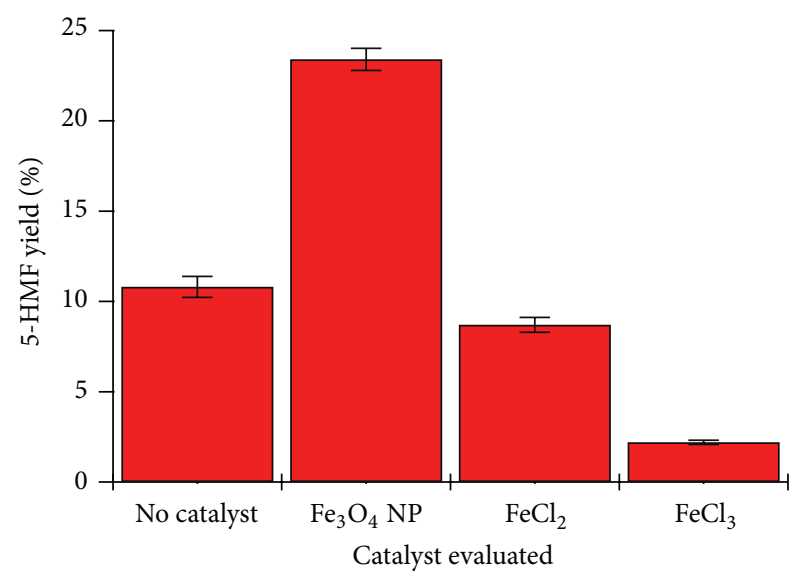

(a)

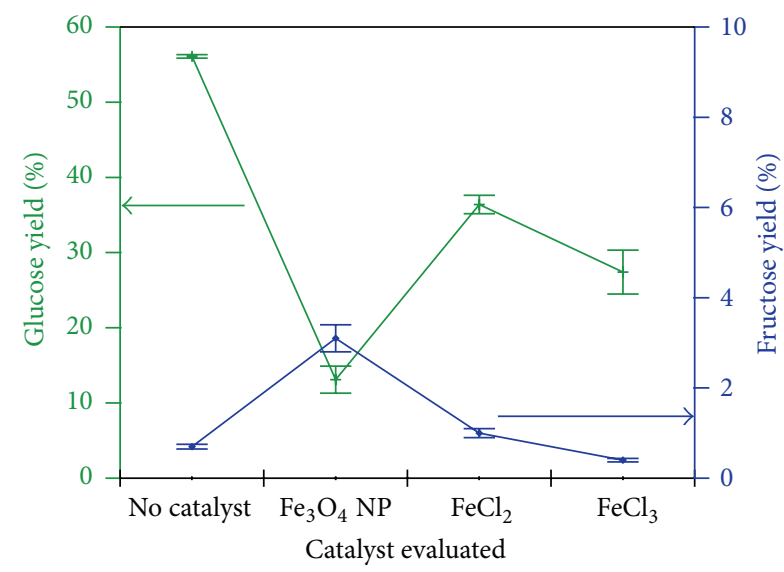

(b)

Figure 3: Effect of $\mathrm{Fe}_{3} \mathrm{O}_{4}$ NPs and iron chloride salts on the conversion of cellobiose to (a) 5-HMF and (b) glucose and fructose. Reaction condition: $10 \mathrm{~mL}$ of $50 \mathrm{mM}$ cellobiose solution and $0.02 \mathrm{~g}$ catalyst at $160^{\circ} \mathrm{C}$ for 24 hours. The yields of other side products such as polymeric humins and organic acids are not included in the charts.

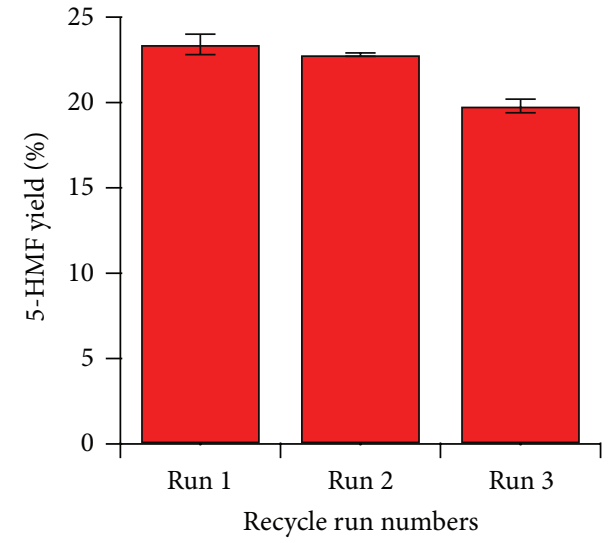

(a)

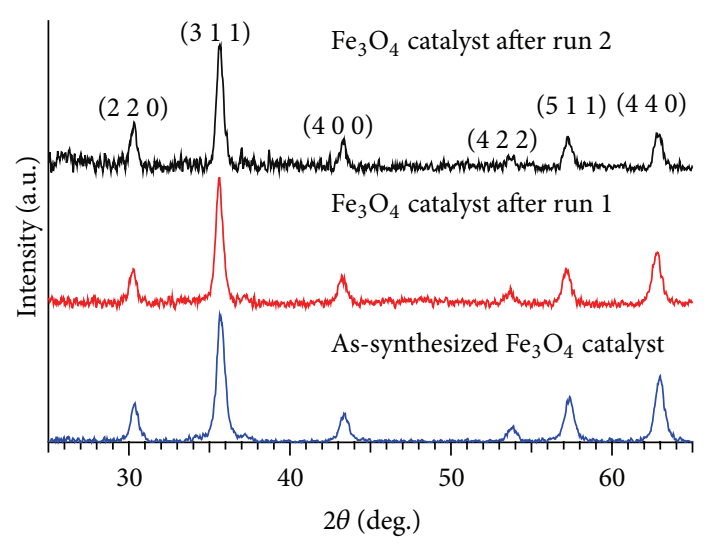

(b)

Figure 4: (a) Catalyst recycling experiments with $\mathrm{Fe}_{3} \mathrm{O}_{4} \mathrm{NPs}$. Reaction condition: $10 \mathrm{~mL}$ of $50 \mathrm{mM}$ cellobiose solution and $0.02 \mathrm{~g} \mathrm{Fe}_{3} \mathrm{O}_{4} \mathrm{NPs}$ at $160^{\circ} \mathrm{C}$ for 24 hours. (b) Comparison of XRD patterns of $\mathrm{Fe}_{3} \mathrm{O}_{4} \mathrm{NPs}$ before and after two recycling runs.

was used. Acids and polymeric humins constituted almost all remaining fractions of the converted cellobiose.

3.3. Recycling of $\mathrm{Fe}_{3} \mathrm{O}_{4} \mathrm{NP}$ Catalyst. $\mathrm{Fe}_{3} \mathrm{O}_{4} \mathrm{NPs}$ were found to be not only catalytically active for this conversion reaction but also easily separable from the liquid products. We evaluated the recyclability of this $\mathrm{Fe}_{3} \mathrm{O}_{4} \mathrm{NP}$ catalyst by performing three successive runs with recovered catalysts. After each reaction run, the catalyst was removed from the reaction solution by magnetic means and washed with deionized water four times. The retrieved catalyst was dried at $80^{\circ} \mathrm{C}$ for an hour in air and then was reused in a follow-up reaction run. The catalytic activity of $\mathrm{Fe}_{3} \mathrm{O}_{4}$ NPs was mostly retained after the recycling runs (Figure 4(a)). However, likely due to the deposition of the reaction by-products such as polymeric humins on the catalyst surface [43], the recycled catalysts became slightly less active after each recycle run and the 5-HMF yields of reactions conducted with the recycled $\mathrm{Fe}_{3} \mathrm{O}_{4}$ NPs decreased by $1-3 \%$ after each recycle run. Nonetheless, the XRD patterns of the $\mathrm{Fe}_{3} \mathrm{O}_{4} \mathrm{NPs}$ after each recycling run remained similar to that before the reaction (Figure 4(b)). This result indicated that $\mathrm{Fe}_{3} \mathrm{O}_{4}$ of the NP catalyst did not exhibit detectable changes into other forms of iron oxides and remained as the active component in these recycle run experiments.

\subsection{Effect of $\mathrm{Fe}_{3} \mathrm{O}_{4} \mathrm{NP}$ Catalyst on the Conversion of Glucose} and Fructose to 5-HMF. Currently, 5-HMF is industrially prepared from fructose instead of the relatively cheap and abundant glucose [16]. In order to convert glucose to 5-HMF, glucose must first be isomerized to fructose by an additional catalyst [44]. This additional step increases the overall manufacturing costs through this reaction scheme. Since both glucose and fructose are identifiable intermediate products in the conversion of cellobiose, we further investigated the effect of applying $\mathrm{Fe}_{3} \mathrm{O}_{4}$ NP catalyst to directly dehydrate 


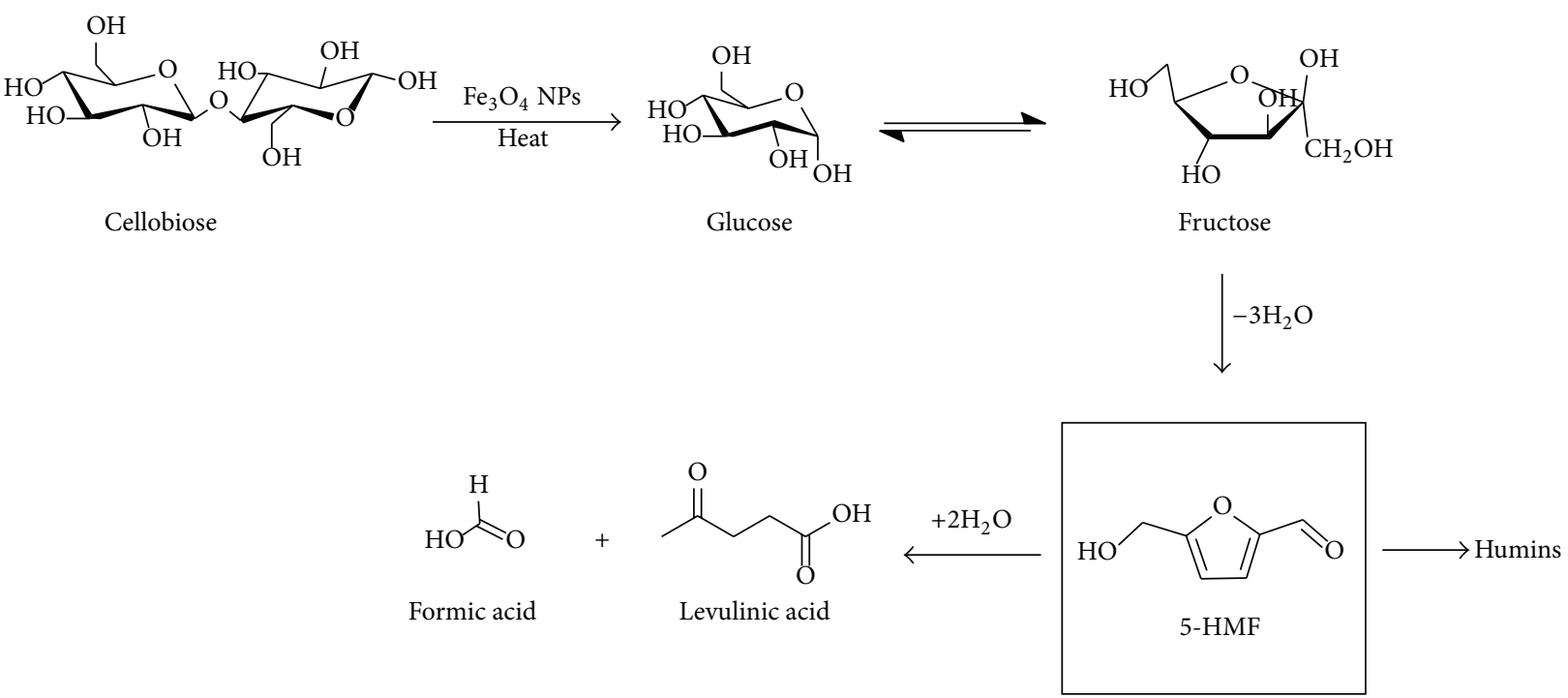

FIGURE 5: Overall proposed reaction schemes for the conversion of cellobiose to 5-HMF and major side products with $\mathrm{Fe}_{3} \mathrm{O}_{4} \mathrm{NP}_{\mathrm{s}}$ atalyst. Side products from glucose and fructose degradation are not shown in the scheme.

glucose and fructose to 5 - $\mathrm{HMF}$ at $160^{\circ} \mathrm{C}$ for 24 hours under hydrothermal conditions.

From our experimental results, glucose was found to achieve $<90 \%$ conversion, but fructose was found to achieve $>99 \%$ conversion irrespective of the presence or absence of the $\mathrm{Fe}_{3} \mathrm{O}_{4} \mathrm{NP}$ catalyst (Tables 1 and 2). Among common monosaccharides, the ability of fructose to undergo complete conversion under acidic and aqueous conditions is well known [15]. Thus, our observed results can be attributed to the relative higher stability of glucose's ring structure, which not only lowers the fraction of open chain forms, but also reduces the rate of formation of enol, a key intermediate in the isomerization reaction to form fructose [45]. Similarly, with $\mathrm{Fe}_{3} \mathrm{O}_{4}$ NPs, glucose to fructose isomerization was enhanced when glucose was used as the starting reagent. Under subcritical water conditions, the reaction temperature is known to directly influence the reaction rate [46]. Hence, the difference in the reaction rates of these two monosaccharides likely caused the variation in the 5-HMF yield at the evaluated temperature. Though reactions with glucose at $160^{\circ} \mathrm{C}$ led to a maximum 5 -HMF yield $(23.6 \pm 0.5 \%)$, the corresponding 5 -HMF produced from fructose degraded further to byproducts at the same evaluated reaction temperature, resulting in an overall lower 5-HMF yield $(17.3 \pm 0.5 \%)$. Nevertheless, the influence of $\mathrm{Fe}_{3} \mathrm{O}_{4} \mathrm{NPs}$ on the conversion of both monosaccharides to 5-HMF was still significant because the product yields were at least two times larger than those of the control experiments (Tables 1 and 2).

3.5. Reaction Mechanism of the Conversion of Cellobiose to 5-HMF Using $\mathrm{Fe}_{3} \mathrm{O}_{4} \mathrm{NP}$ Catalysts. Through examining the presence of various reaction products, we postulated that the hydrothermal conversion of cellobiose to 5-HMF with the $\mathrm{Fe}_{3} \mathrm{O}_{4}$ NP catalyst primarily followed a common reaction scheme for the conversion of oligosaccharides to 5-HMF and
TABLE 1: Effect of $\mathrm{Fe}_{3} \mathrm{O}_{4}$ NPs on glucose conversion to 5-HMF. Reaction condition: $10 \mathrm{~mL}$ of $100 \mathrm{mM}$ glucose solution and $0.02 \mathrm{~g} \mathrm{Fe}_{3} \mathrm{O}_{4}$ $\mathrm{NPs}$ at $160^{\circ} \mathrm{C}$ for 24 hours

\begin{tabular}{lccc}
\hline Catalyst & $\begin{array}{c}\text { Glucose } \\
\text { conversion } \\
(\%)\end{array}$ & Fructose yield (\%) & 5-HMF yield (\%) \\
\hline No catalyst & $46.4 \pm 2.2$ & $<1$ & $11.9 \pm 0.7$ \\
$\mathrm{Fe}_{3} \mathrm{O}_{4} \mathrm{NPs}$ & $89.2 \pm 0.1$ & $2.6 \pm 0.2$ & $23.6 \pm 0.5$ \\
\hline
\end{tabular}

TABLE 2: Effect of $\mathrm{Fe}_{3} \mathrm{O}_{4}$ NPs on fructose conversion to 5HMF. Reaction conditions: $10 \mathrm{~mL}$ of $100 \mathrm{mM}$ fructose solution and $0.02 \mathrm{~g} \mathrm{Fe}_{3} \mathrm{O}_{4} \mathrm{NPs}$ at $160^{\circ} \mathrm{C}$ for 24 hours.

\begin{tabular}{lccc}
\hline Catalyst & $\begin{array}{c}\text { Fructose } \\
\text { conversion } \\
(\%)\end{array}$ & Glucose yield (\%) & 5-HMF yield (\%) \\
\hline No catalyst & $>99$ & $<1$ & $8.9 \pm 0.1$ \\
$\mathrm{Fe}_{3} \mathrm{O}_{4} \mathrm{NPs}$ & $>99$ & $<1$ & $17.3 \pm 0.5$ \\
\hline
\end{tabular}

side products (Figure 5 ). In our case, cellobiose was proposed to first undergo hydrolysis to form glucose. Under the hydrothermal condition, glucose then underwent the reversible isomerization (or the Lobry de Bruyn-Alberda van Ekenstein (LBAE) transformation) $[40,46,47]$ to fructose and other ring-opened unstable intermediates which eventually dehydrated to 5 -HMF $[45,48]$. This was supported by the HPLC data which showed the presence of both glucose and fructose among the reaction products. The unstable intermediates, however, could not be isolated from the reaction mixture. Bifunctional metal oxides such as titania which contain both Lewis acid and base sites are known to improve glucose to fructose isomerization along with 5-HMF production [30]. The improvements in 5-HMF yields and glucose to fructose 
isomerization in our case can similarly be attributed to the amphoteric nature of $\mathrm{Fe}_{3} \mathrm{O}_{4}$ [49].

In addition, acid by-products including formic acid, levulinic acid, lactic acid, acetic acid $(<11.1 \%)$, and other side products such as hydroxyacetone and 1,6-anhydroglucose were identified in minute amounts $(<1.5 \%)$ by HPLC. The presence of these acid by-products corroborated well the decrease in the $\mathrm{pH}$ of the reaction mixture from $\mathrm{ca} .6$ to $\mathrm{ca} .3$ after the reaction. The presence of these acids was not surprising because, in an aqueous, acidic medium, 5-HMF can be rehydrated to form levulinic and formic acid [50]. Acetic acid and lactic acid, potential retroaldol reaction products of glucose, were also detected by HPLC [51]. Hydroxyacetone and 1,6-anhydroglucose are known to be degradation products of fructose [46] and glucose [48], respectively. The color of the reaction products was always observed to attain different shades of brown, suggesting the formation of humins, insoluble polymers formed from 5-HMF [50]. Further, Lewis acidity was enhanced in iron oxide NPs because of the high degree of Fe-coordinative unsaturation in the oxide which improved their overall activity for isomerization reactions [52].

\section{Conclusion}

Magnetite nanoparticles $\left(\mathrm{Fe}_{3} \mathrm{O}_{4} \mathrm{NPs}\right.$ ) were demonstrated to be effective catalysts at converting cellobiose to 5-HMF in an aqueous medium under hydrothermal conditions. The highest 5-HMF yields of $23.4 \pm 0.6 \%$ were obtained at $160^{\circ} \mathrm{C}$ for 24 hours of reaction time and at a catalyst loading of just $0.02 \mathrm{~g}$. This catalyst outperformed common iron salts $\left(\mathrm{FeCl}_{2}\right.$ and $\left.\mathrm{FeCl}_{3}\right)$ of equal loading in producing 5 - $\mathrm{HMF}$ in this reaction. Since $\mathrm{Fe}_{3} \mathrm{O}_{4}$ NPs can be easily separable using magnetic methods and are demonstrated to be recyclable for this reaction, these environmentally friendly catalysts have excellent potential to be used for dehydrating both fructose and recalcitrant glucose to 5-HMF with comparable yields upon further optimized studies.

\section{Conflict of Interests}

The authors declare that there is no conflict of interests regarding the publication of this paper.

\section{Acknowledgments}

The authors thank the Research Council of the University of Nebraska-Lincoln (UNL) for the funding support and the Nebraska Center for Materials and Nanoscience and the Morrison Microscopy Core Research Facility for the use of their facilities. The authors are grateful to Lukasz Gauza at UNL for his help with the BET measurements.

\section{References}

[1] W. Wu, Z. Wu, T. Yu, C. Jiang, and W.-S. Kim, "Recent progress on magnetic iron oxide nanoparticles: synthesis, surface functional strategies and biomedical applications," Science and Technology of Advanced Materials, vol. 16, no. 2, Article ID 023501, 2015.
[2] Y. Zhang, L. Zhang, X. Song et al., "Synthesis of superparamagnetic iron oxide nanoparticles modified with MPEG-PEI via photochemistry as new MRI contrast agent," Journal of Nanomaterials, vol. 2015, Article ID 417389, 6 pages, 2015.

[3] X. Gu, Y. Zhang, H. Sun, X. Song, C. Fu, and P. Dong, "Musselinspired polydopamine coated iron oxide nanoparticles for biomedical application," Journal of Nanomaterials, vol. 2015, Article ID 154592, 12 pages, 2015.

[4] T. Zeng, W.-W. Chen, C. M. Cirtiu, A. Moores, G. Song, and C.-J. $\mathrm{Li}$, " $\mathrm{Fe}_{3} \mathrm{O}_{4}$ nanoparticles: a robust and magnetically recoverable catalyst for three-component coupling of aldehyde, alkyne and amine," Green Chemistry, vol. 12, no. 4, pp. 570-573, 2010.

[5] R. S. Varma, "Nano-catalysts with magnetic core: sustainable options for greener synthesis," Sustainable Chemical Processes, vol. 2, article 11, 2014.

[6] M. B. Gawande, P. S. Branco, and R. S. Varma, "Nano-magnetite $\left(\mathrm{Fe}_{3} \mathrm{O}_{4}\right)$ as a support for recyclable catalysts in the development of sustainable methodologies," Chemical Society Reviews, vol. 42, no. 8, pp. 3371-3393, 2013.

[7] L. Gao, J. Zhuang, L. Nie et al., "Intrinsic peroxidase-like activity of ferromagnetic nanoparticles," Nature Nanotechnology, vol. 2, no. 9, pp. 577-583, 2007.

[8] H. Jung, H. Park, J. Kim et al., "Preparation of biotic and abiotic iron oxide nanoparticles (IOnPs) and their properties and applications in heterogeneous catalytic oxidation," Environmental Science and Technology, vol. 41, no. 13, pp. 4741-4747, 2007.

[9] N. Mei, B. Liu, J. Zheng, K. Lv, D. Tang, and Z. Zhang, "A novel magnetic palladium catalyst for the mild aerobic oxidation of 5-hydroxymethylfurfural into 2,5-furandicarboxylic acid in water," Catalysis Science \& Technology, vol. 5, no. 6, pp. 31943202, 2015.

[10] S. Wang, Z. Zhang, B. Liu, and J. Li, "Silica coated magnetic $\mathrm{Fe}_{3} \mathrm{O}_{4}$ nanoparticles supported phosphotungstic acid: a novel environmentally friendly catalyst for the synthesis of 5-ethoxymethylfurfural from 5-hydroxymethylfurfural and fructose," Catalysis Science and Technology, vol. 3, no. 8, pp. 2104-2112, 2013.

[11] D.-M. Lai, L. Deng, Q.-X. Guo, and Y. Fu, "Hydrolysis of biomass by magnetic solid acid," Energy and Environmental Science, vol. 4, no. 9, pp. 3552-3557, 2011.

[12] Y. Xiong, Z. Zhang, X. Wang, B. Liu, and J. Lin, "Hydrolysis of cellulose in ionic liquids catalyzed by a magneticallyrecoverable solid acid catalyst," Chemical Engineering Journal, vol. 235, pp. 349-355, 2014.

[13] S. Yin, J. Sun, B. Liu, and Z. Zhang, "Magnetic material grafted cross-linked imidazolium based polyionic liquids: an efficient acid catalyst for the synthesis of promising liquid fuel 5ethoxymethylfurfural from carbohydrates," Journal of Materials Chemistry A, vol. 3, no. 9, pp. 4992-4999, 2015.

[14] S. Wang, Z. Zhang, and B. Liu, "Catalytic conversion of fructose and 5-hydroxymethylfurfural into 2,5-furandicarboxylic acid over a recyclable $\mathrm{Fe}_{3} \mathrm{O}_{4}-\mathrm{CoO}_{x}$ magnetite nanocatalyst," ACS Sustainable Chemistry \& Engineering, vol. 3, no. 3, pp. 406-412, 2015.

[15] L. Hu, X. Tang, Z. Wu et al., "Magnetic lignin-derived carbonaceous catalyst for the dehydration of fructose into 5hydroxymethylfurfural in dimethylsulfoxide," Chemical Engineering Journal, vol. 263, pp. 299-308, 2015.

[16] BAC Reports, 5-Hydroxymethylfurfural (CAS 67-47-0) Market Research Report 2015, May 2015.

[17] G. W. Huber, Breaking the Chemical and Engineering Barriers to Lignocellulosic Biofuels: Next Generation Hydrocarbon 
Biorefineries, University of Massachusetts, Amherst, Mass, USA, 2008.

[18] J. J. Bozell and G. R. Petersen, “Technology development for the production of biobased products from biorefinery carbohydrates-the US Department of Energy's “Top 10" revisited," Green Chemistry, vol. 12, no. 4, pp. 539-554, 2010.

[19] M. Dashtban, A. Gilbert, and P. Fatehi, "Recent advancements in the production of hydroxymethylfurfural," RSC Advances, vol. 4, no. 4, pp. 2037-2050, 2014.

[20] L. Yang, G. Tsilomelekis, S. Caratzoulas, and D. G. Vlachos, "Mechanism of Brønsted Acid-Catalyzed Glucose Dehydration," ChemSusChem, vol. 8, no. 8, pp. 1334-1341, 2015.

[21] H. Zhao, J. E. Holladay, H. Brown, and Z. C. Zhang, "Metal chlorides in ionic liquid solvents convert sugars to 5hydroxymethylfurfural," Science, vol. 316, no. 5831, pp. 15971600, 2007.

[22] Y. J. Pagán-Torres, T. Wang, J. M. R. Gallo, B. H. Shanks, and J. A. Dumesic, "Production of 5-hydroxymethylfurfural from glucose using a combination of Lewis and Brønsted acid catalysts in water in a biphasic reactor with an alkylphenol solvent," ACS Catalysis, vol. 2, no. 6, pp. 930-934, 2012.

[23] K. D. O. Vigier and F. Jérôme, "Heterogeneously-catalyzed conversion of carbohydrates," in Carbohydrates in Sustainable Development II, A. P. Rauter, P. Vogel, and Y. Queneau, Eds., pp. 63-92, Springer, Heidelberg, Germany, 2010.

[24] S. P. Teong, G. Yi, and Y. Zhang, "Hydroxymethylfurfural production from bioresources: past, present and future," Green Chemistry, vol. 16, no. 4, pp. 2015-2026, 2014.

[25] H. V. Lee, S. B. Hamid, and S. K. Zain, "Conversion of lignocellulosic biomass to nanocellulose: structure and chemical process," The Scientific World Journal, vol. 2014, Article ID 631013, 20 pages, 2014.

[26] Z. C. Gernhart, A. Bhalkikar, J. J. Burke et al., "One-pot conversion of cellobiose to mannose using a hybrid phosphotungstic acid-cerium oxide catalyst," RSC Advances, vol. 5, no. 36, pp. 28478-28486, 2015.

[27] Y.-H. Percival Zhang, J. Cui, L. R. Lynd, and L. R. Kuang, "A transition from cellulose swelling to cellulose dissolution by o-phosphoric acid: evidence from enzymatic hydrolysis and supramolecular structure," Biomacromolecules, vol. 7, no. 2, pp. 644-648, 2006.

[28] V. Degirmenci, E. A. Pidko, P. C. M. M. Magusin, and E. J. M. Hensen, "Towards a selective heterogeneous catalyst for glucose dehydration to 5-hydroxymethylfurfural in water: $\mathrm{CrCl}_{2}$ catalysis in a thin immobilized ionic liquid layer," Chem CatChem, vol. 3, no. 6, pp. 969-972, 2011.

[29] R.-J. van Putten, J. C. van der Waal, E. de Jong, C. B. Rasrendra, H. J. Heeres, and J. G. de Vries, "Hydroxymethylfurfural, a versatile platform chemical made from renewable resources," Chemical Reviews, vol. 113, no. 3, pp. 1499-1597, 2013.

[30] M. Watanabe, Y. Aizawa, T. Iida et al., "Glucose reactions with acid and base catalysts in hot compressed water at $473 \mathrm{~K}$," Carbohydrate Research, vol. 340, no. 12, pp. 1925-1930, 2005.

[31] F. S. Asghari and H. Yoshida, "Acid-catalyzed production of 5hydroxymethyl furfural from D-fructose in subcritical water," Industrial and Engineering Chemistry Research, vol. 45, no. 7, pp. 2163-2173, 2006.

[32] F. Ilgen, D. Ott, D. Kralisch, C. Reil, A. Palmberger, and B. König, "Conversion of carbohydrates into 5-hydroxymethylfurfural in highly concentrated low melting mixtures," Green Chemistry, vol. 11, no. 12, pp. 1948-1954, 2009.
[33] A. Pourjavadi, S. H. Hosseini, M. Doulabi, S. M. Fakoorpoor, and F. Seidi, "Multi-Layer functionalized poly(ionic liquid) coated magnetic nanoparticles: highly recoverable and magnetically separable brønsted acid catalyst," ACS Catalysis, vol. 2, no. 6, pp. 1259-1266, 2012.

[34] A. Sluiter, B. Hames, R. Ruiz, C. Scarlata, J. Sluiter, and D. Templeton, "Determination of sugars, byproducts, and degradation products in liquid fraction process samples," Tech. Rep. NREL/TP-510-42623, National Renewable Energy Laboratory, 2008.

[35] G. Marcotullio, E. Krisanti, J. Giuntoli, and W. de Jong, "Selective production of hemicellulose-derived carbohydrates from wheat straw using dilute $\mathrm{HCl}$ or $\mathrm{FeCl}_{3}$ solutions under mild conditions. X-ray and thermo-gravimetric analysis of the solid residues," Bioresource Technology, vol. 102, no. 10, pp. 5917-5923, 2011.

[36] L. Liu, J. Sun, C. Cai, S. Wang, H. Pei, and J. Zhang, "Corn stover pretreatment by inorganic salts and its effects on hemicellulose and cellulose degradation," Bioresource Technology, vol. 100, no. 23, pp. 5865-5871, 2009.

[37] C. M. Cai, N. Nagane, R. Kumar, and C. E. Wyman, "Coupling metal halides with a co-solvent to produce furfural and 5$\mathrm{HMF}$ at high yields directly from lignocellulosic biomass as an integrated biofuels strategy," Green Chemistry, vol. 16, no. 8, pp. 3819-3829, 2014.

[38] O. Bobleter, "Hydrothermal degradation of polymers derived from plants," Progress in Polymer Science, vol. 19, no. 5, pp. 797841, 1994.

[39] M. Sasaki, B. Kabyemela, R. Malaluan et al., "Cellulose hydrolysis in subcritical and supercritical water," Journal of Supercritical Fluids, vol. 13, no. 1-3, pp. 261-268, 1998.

[40] B. M. Kabyemela, T. Adschiri, R. M. Malaluan, and K. Arai, "Glucose and fructose decomposition in subcritical and supercritical water: detailed reaction pathway, mechanisms, and kinetics," Industrial and Engineering Chemistry Research, vol. 38, no. 8, pp. 2888-2895, 1999.

[41] Y. L. Song, Y. H. Qu, C. P. Huang, L. H. Ge, Y. X. Li, and B. H. Chen, "Single-step conversion of cellobiose to 5-Hydroxymethylfurfural (5-HMF) catalyzed by poly ionic liquid," Advanced Materials Research, vol. 1004-1005, pp. 885-890, 2014.

[42] F. Liu, M. Audemar, K. D. O. De Oliveira Vigier et al., "Selectivity enhancement in the aqueous acid-catalyzed conversion of glucose to 5-hydroxymethylfurfural induced by choline chloride," Green Chemistry, vol. 15, no. 11, pp. 3205-3213, 2013.

[43] A. Mukherjee, M.-J. Dumont, and V. Raghavan, "Review: sustainable production of hydroxymethylfurfural and levulinic acid: challenges and opportunities," Biomass and Bioenergy, vol. 72, pp. 143-183, 2015.

[44] R.-J. van Putten, J. N. M. Soetedjo, E. A. Pidko et al., "Dehydration of different ketoses and aldoses to 5-hydroxymethylfurfural," ChemSusChem, vol. 6, no. 9, pp. 1681-1687, 2013.

[45] A. A. Rosatella, S. P. Simeonov, R. F. M. Frade, and C. A. M. Afonso, "5-hydroxymethylfurfural (HMF) as a building block platform: biological properties, synthesis and synthetic applications," Green Chemistry, vol. 13, no. 4, pp. 754-793, 2011.

[46] M. Möller, F. Harnisch, and U. Schröder, "Microwave-assisted hydrothermal degradation of fructose and glucose in subcritical water," Biomass and Bioenergy, vol. 39, pp. 389-398, 2012.

[47] T. M. Aida, K. Tajima, M. Watanabe et al., "Reactions of dfructose in water at temperatures up to $400{ }^{\circ} \mathrm{C}$ and pressures up to $100 \mathrm{MPa}$," Journal of Supercritical Fluids, vol. 42, no. 1, pp. 110-119, 2007. 
[48] A. A. Peterson, F. Vogel, R. P. Lachance, M. Fröling, M. J. Antal Jr., and J. W. Tester, "Thermochemical biofuel production in hydrothermal media: a review of sub- and supercritical water technologies," Energy and Environmental Science, vol. 1, no. 1, pp. 32-65, 2008.

[49] R. M. Cornell and U. Schwertmann, "Surface chemistry and colloidal stability," in The Iron Oxides: Structure, Properties, Reactions, Occurences and Uses, pp. 221-252, Wiley, Weinheim, Germany, 1996.

[50] M. J. Antal Jr., W. S. L. Mok, and G. N. Richards, "Mechanism of formation of 5-(hydroxymethyl)-2-furaldehyde from Dfructose and sucrose," Carbohydrate Research, vol. 199, no. 1, pp. 91-109, 1990.

[51] T. M. Aida, Y. Sato, M. Watanabe et al., "Dehydration of dglucose in high temperature water at pressures up to $80 \mathrm{MPa}$," Journal of Supercritical Fluids, vol. 40, no. 3, pp. 381-388, 2007.

[52] A. Gervasini, C. Messi, P. Carniti, A. Ponti, N. Ravasio, and F. Zaccheria, "Insight into the properties of Fe oxide present in high concentrations on mesoporous silica," Journal of Catalysis, vol. 262, no. 2, pp. 224-234, 2009. 

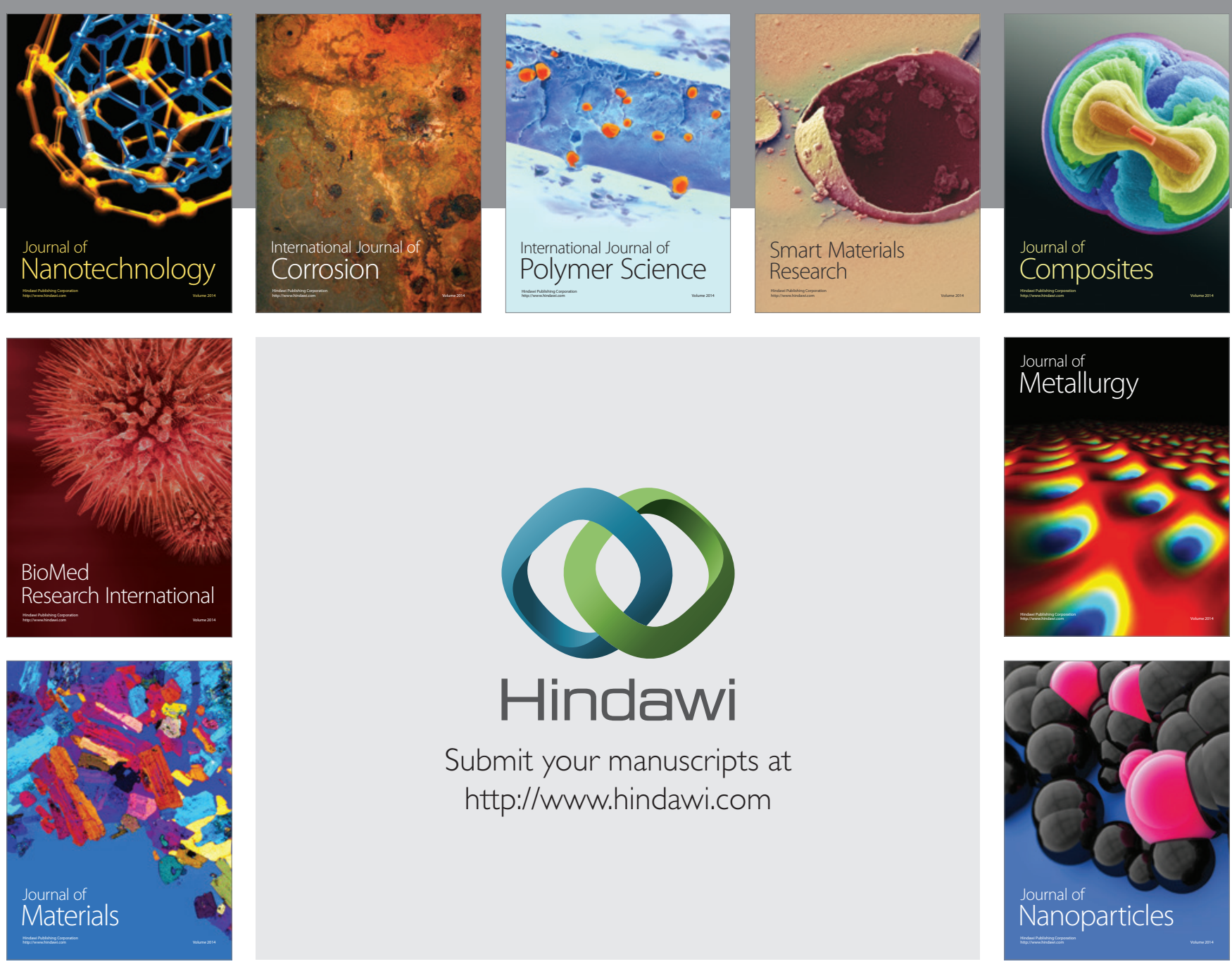

Submit your manuscripts at http://www.hindawi.com
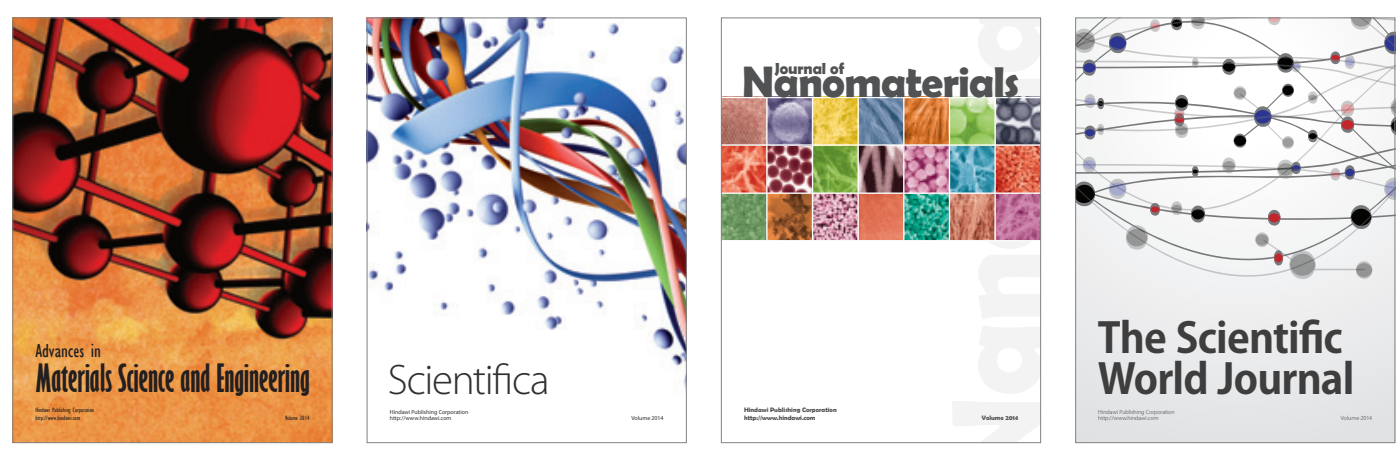

\section{The Scientific World Journal}
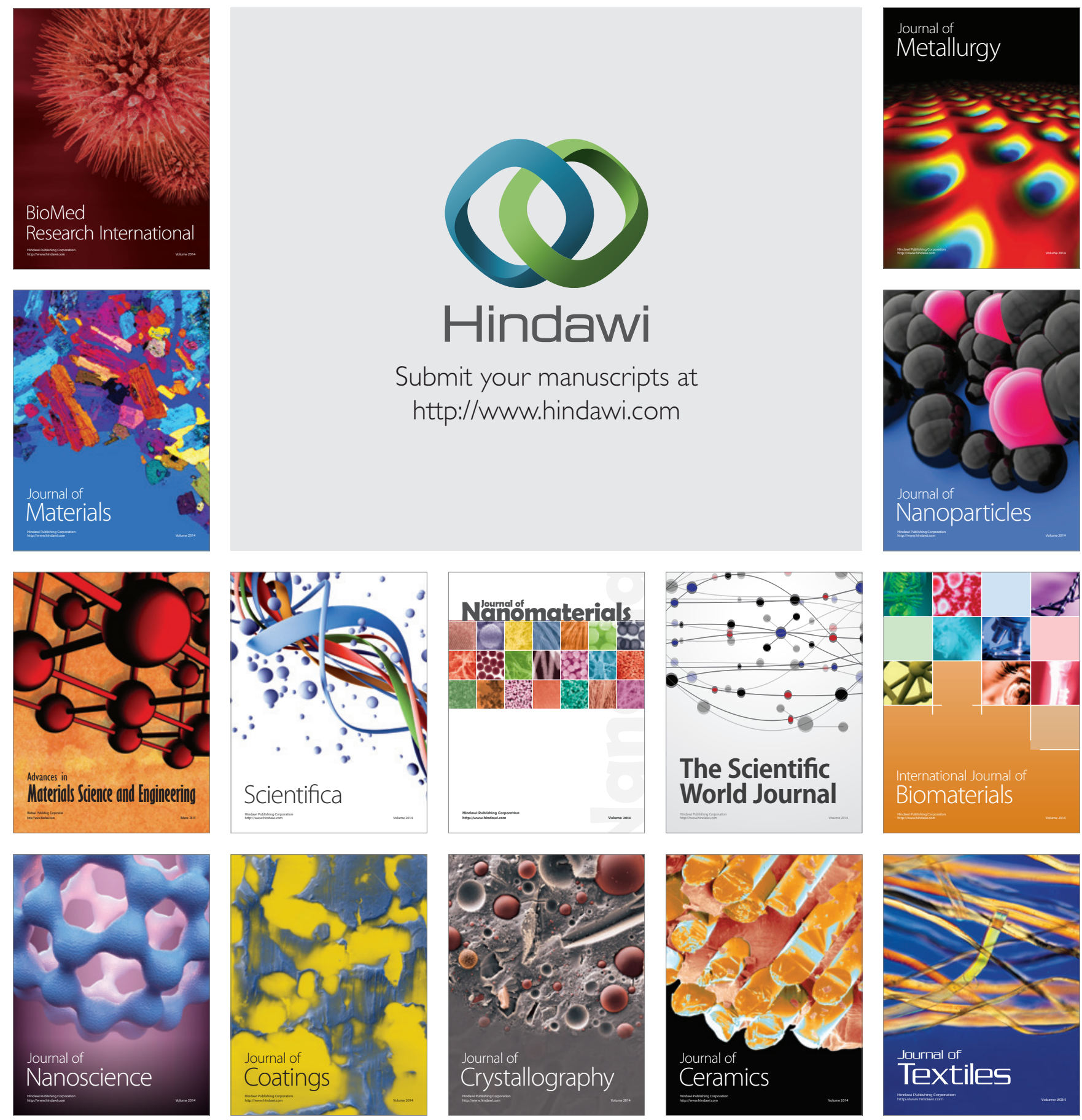